\title{
Characteristics of Early-Winter Caribou, Rangifer tarandus caribou, Feeding Sites in the Southern Purcell Mountains, British Columbia
}

\author{
Trevor A. Kinley ${ }^{1,2}$, John Bergenske ${ }^{3}$, Julie-Anne Davies ${ }^{4}$, and David QuinN ${ }^{5}$ \\ ${ }^{1}$ Sylvan Consulting Ltd., RR5 3519 Toby Creek Road, Invermere, British Columbia V0A 1K5 Canada \\ ${ }^{2}$ Corresponding author: e-mail: sylvan@ rockies.net \\ ${ }^{3}$ Box 84, Skookumchuck, British Columbia V0B 2E0 Canada \\ ${ }^{4} 465$ Creston Street, Kimberley, British Columbia V1A 2M4 Canada \\ 52410 DeWolfe Street, Kimberley, British Columbia V1A 1P9 Canada
}

\begin{abstract}
Kinley, Trevor A., John Bergenske, Julie-Anne Davies, and David Quinn. 2003. Characteristics of early-winter Caribou, Rangifer tarandus caribou, feeding sites in the southern Purcell Mountains, British Columbia. Canadian Field-Naturalist 117(3): 352-359.
\end{abstract}

\begin{abstract}
Mountain Caribou are a rare ecotype of Woodland Caribou (Rangifer tarandus caribou) inhabiting the high-snowfall region of southeastern British Columbia, and are defined by their late-winter reliance on arboreal hair lichen of the genus Bryoria. During early winter, there is considerable variation in habitat use among populations. We snow-trailed Caribou in the southern Purcell Mountains during early winter to determine foraging patterns for the Purcell population. When snow was $\leq 51 \mathrm{~cm}$ deep, Caribou fed on Grouseberry (Vaccinium scoparium), the terrestrial lichen Cladonia, and arboreal lichens of the genus Bryoria. When snow was $\geq 62 \mathrm{~cm}$ deep, they ate exclusively arboreal lichens. In both periods, Caribou ate arboreal lichen from essentially every downed tree or branch encountered and fed with a higher intensity at downed trees than standing trees. During the low-snow period, Caribou fed at fewer trees but used those with greater lichen abundance, and fed more intensively at each, compared to the deep-snow period. In comparison to trees occurring on the foraging path but at which Caribou did not feed, those from which arboreal lichen was foraged intensively were of larger diameter, had greater lichen abundance, and were more likely to be Subalpine Fir (Abies lasiocarpa) or Engelmann Spruce (Picea engelmannii) and less likely to be Whitebark Pine (Pinus albicaulis), Lodgepole Pine (P. contorta) or Alpine Larch (Larix lyalli). The shift in diet between the low-snow and deep-snow periods reflected two modes of foraging within the early winter period, distinct from one another and apparently also distinct from the late-winter season. Management for early-winter habitat will require retention of some commercially significant forest across extensive areas, both near the subalpine forest - subalpine parkland ecotone and lower in the subalpine forest.
\end{abstract}

Key Words: Woodland Caribou, Rangifer tarandus caribou, habitat, early winter, Grouseberry, Vaccinium scoparium, lichen, Bryoria, Purcell Mountains, British Columbia.

The ecotype of Woodland Caribou (Rangifer tarandus caribou) occurring in the wetter portions of southeast British Columbia, northern Idaho and northeastern Washington is known in British Columbia as Mountain Caribou (Heard and Vagt 1998) or Mountain/Arboreal Caribou (Edmonds 1991). This ecotype has a population of 1900 distributed in 13 populations (Hatter et al. 2002*). It is on British Columbia's red list, indicating it is "imperilled provincially because of extreme rarity or because of some factor(s) making it especially vulnerable to extinction" (Conservation Data Centre 2003*). It is also included with some populations of another ecotype on Canada's threatened list (Committee on the Status of Endangered Wildlife in Canada 2002*), and is listed as endangered in the USA (United States Fish and Wildlife Service 1994*). Mountain Caribou differ from other Woodland Caribou ecotypes in being almost entirely dependent upon arboreal hair lichen (mainly horsehair lichens, especially Bryoria spp.) rather than terrestrial lichen for late-winter food, because of the extremely deep snowpacks at higher elevations in this region (Edwards et al. 1960; Stevenson and Hatler 1985). Deep snow in late winter makes

\footnotetext{
* See Documents Cited section.
}

cratering for terrestrial lichen or other ground-based foods difficult or impossible. However, deep snow also provides the necessary lift to reach Bryoria, which is more abundant $>2 \mathrm{~m}$ above the ground (Rominger and Oldemeyer 1990; Goward 1998). This food source is generally abundant only on old conifer trees (Goward 1998), which is one of the reasons that Mountain Caribou are considered to be reliant on oldgrowth forest. These forests also have potentially high timber values.

Early-winter foraging differs from that of late winter in several respects. Until snowpacks deepen and consolidate sufficiently to allow Caribou to readily obtain arboreal lichen from standing trees, they also (1) make use of arboreal lichen available as litterfall on the snow's surface or on windthrown trees or branches (Stevenson et al. 2001), and (2) in many locations crater through snow to eat forbs such as Foamflower (Tiarella spp.) and Mitrewort (Mitella spp.), terrestrial lichens including Lungwort (Lobaria pulmonaria), various pelt lichens (Peltigera spp.) and Cladonia (Cladonia spp.), shrubs, especially Falsebox (Pachistima myrsinites), Bunchberry (Cornus canadensis), Twinflower (Linnaea borealis) and various huckleberries (Vaccinium spp.), 
and graminoids (Edwards and Ritcey 1960; Freddy 1974; Bloomfield 1979; Antifeau 1987; Simpson et al. 1987; Rominger and Oldemeyer 1990; McLellan and Flaa 1993*; Mowat et al. 1998*; Terry et al. 2000, Stevenson et al. 2001). The early-winter season typically lasts from November through mid-January, and is associated with shifts to lower elevations (Stevenson et al. 2001; Apps et al. 2001). In sum, winter seasons for Mountain Caribou include early winter up to about mid-January, during which forage includes both arboreal lichen and ground-based foods at low to moderate elevations, then late winter when deep, consolidated snowpacks at higher elevations provide sufficient lift to more readily reach the abundant arboreal lichens higher in trees.

The southern Purcell Mountains population is at the southeastern limit of remaining Mountain Caribou distribution. This population has recently declined to about 20 animals (Kinley and Apps 2001) and is isolated. Habitat models for the southern Purcell Mountains have been created at the landscape and stand scale (Apps and Kinley 2000*; Kinley and Apps $2000 *$, providing guidance for habitat protection based on characteristics of forest stands and topography. The models indicate that the average downward movement during early winter in the southern Purcell Mountains is slight, with most activity occurring in forests close to treeline. However, those models were at spatial scales coarser than those at which detailed foraging decisions are made, so many of the variables used may have been surrogates for the attributes Caribou selected. Snow-trailing investigations of Mountain Caribou have been conducted in some parts of British Columbia to determine foraging strategies at fine spatial scales (McLellan and Flaa 1993*; Ashcroft 1997*; Mowat et al. 1998*; Terry et al. 2000). However, these studies may not be applicable in the southern Purcell Mountains due to differences in physiography, climate and vegetation, and the considerable variation in early-winter habitat use employed by Mountain Caribou (Terry et al. 2000, Apps et al. 2001, Stevenson et al. 2001). Given the conservation concerns for Mountain Caribou generally and the southern Purcell Mountains population in particular, a better understanding of habitat use patterns would be beneficial. Therefore, we conducted a snow trailing investigation during early winter in the southern Purcell Mountains to determine local patterns of Caribou feeding-site selection.

\section{Study Area}

Within our $5000-\mathrm{km}^{2}$ study area, physiography ranges from subdued ridges to high ridges and mountains, with elevations of 530 to $2850 \mathrm{~m}$. The climate of this area is somewhat drier than the rest of Mountain Caribou range (Curran et al. 1992), but there is a general trend within the study area towards increasing precipitation from northeast to southwest, and from lower to higher elevations. In areas with less precipi- tation, the trend in climax tree species is: Douglas-fir (Pseudotsuga menziesii) at elevations below about $1150 \mathrm{~m}$; hybrid White Spruce (Picea glauca $\times$ engelmannii) to about $1600 \mathrm{~m}$; a closed-canopy forest of Engelmann Spruce (P. engelmannii) and Subalpine Fir (Abies lasiocarpa) to about $2100 \mathrm{~m}$ (hereafter "subalpine forest"); open stands of Subalpine Fir, Whitebark Pine (Pinus albicaulis) and Alpine Larch (Larix lyalli) to about $2600 \mathrm{~m}$ ("subalpine parkland"); then alpine tundra over about $2600 \mathrm{~m}$ (Curran et al. 1992). In moister areas, the subalpine forest occurs at elevations between about 1550 and $1950 \mathrm{~m}$, and land below it has climax forests of Western Redcedar (Thuja plicata) and Western Hemlock (Tsuga heterophylla). Lodgepole Pine (Pinus contorta) is a common fire-successional species in all forested zones. It typically occurs in pure stands when young, but often persists in mixed stands at climax.

\section{Methods}

We located radiocollared Caribou $(\mathrm{n}=10)$ from 10 November 1998 through 5 January 1999 using telemetry-equipped aircraft. This was on a nominal weekly schedule although inclement weather made the actual schedule variable. On the first day following each flight we randomly selected one of the radiocollared animals, then approached that animal or the group in which it occurred from the ground until the first trail was observed in the snow. We followed the trail in the direction of Caribou travel unless it appeared to have been made that day, in which case we traveled in the reverse direction to avoid displacing the Caribou. Individual Caribou seldom diverged far from the group's trail but when this occurred, we followed the most distinct path (presumably having been made by the greatest number of animals). We recorded snow depth and Caribou sinking depth at the first track encountered and every $500 \mathrm{~m}$ thereafter, with distances measured using a hip-chain. We used the difference between snow depth and sinking depth to determine the lift provided by the snowpack. Along the trail, we recorded all feeding sites, which we defined as either a crater dug by Caribou to reach ground-based foods, or a tree (standing or downed) or downed branch from which Caribou had eaten arboreal lichen. We noted the distance of each feeding site from the previous one, and classified each as being of either a single type (arboreal lichen on a standing tree, arboreal lichen on a downed tree, arboreal lichen on a downed branch, shrubs, forbs, or terrestrial lichen), or a combination of types (shrub-terrestrial lichen, standing tree-shrub, or standing tree-terrestrial lichen). Terrestrial feeding sites were evident as craters in the snow, usually with bite marks evident on the vegetation and often with fragments of broken vegetation present on the snow or ground surface. Due to the structure of arboreal hair lichens and the breakage of arboreal lichens even without foraging activity, it was usually not possible to determine with certainty whether bites had been 
taken from arboreal lichen clumps, so trampling of the snow within reach of them was assumed to correspond to feeding events. For standing-tree and downed-tree sites, we classified the tree according to species, arboreal lichen abundance (ranging from estimated values of 0 to $>625 \mathrm{~g}$ of lichen within $4.5 \mathrm{~m}$ of the ground, on a 0 to 5 scale; Armleder et al. 1992), whether live or dead, and diameter at breast height $(1.3 \mathrm{~m}$ above ground). For feeding sites of all types, we coded the intensity of feeding (McLellan and Flaa 1993*) as 2 (low; two or fewer steps off of trail toward feeding site), 3 (moderate; $<50 \%$ of area around tree, branch or crater tracked and individual hoof prints visible) or 4 (high; $>50 \%$ of area trampled). In addition, we recorded all downed branches or downed trees at which feeding had not occurred (code 1) if they were within $1 \mathrm{~m}$ of the trail centerline and were exposed above the snow. We also classified the first unused standing tree within $1 \mathrm{~m}$ of the trail every $200 \mathrm{~m}$. We continued trailing as long as light permitted each day. One of the remaining groups having a radiocollared animal was chosen at random for tracking on the following days for up to three days after each radiotelemetry flight, after which movements since the date of aerial telemetry made locating Caribou impractical. All trailing occurred within subalpine forest and subalpine parkland, and was within mature or oldgrowth forest.

Radiocollared Caribou usually occurred in groups $(\leq 4)$, so the identity and sex of the Caribou making the trail we followed were generally not known and we did not stratify the analysis by sex. We summarized use of each feeding type with respect to the earlier versus later portion of our data-collection period to define two distinct foraging periods or foraging modes, then assessed differences in: (1) intensity of arboreal lichen feeding at standing versus downed trees; (2) environmental and feeding measures between the two foraging periods (snow depth, lift, elevation, arboreal lichen abundance, arboreal lichen-feeding intensity, distance between trees on which arboreal lichen feeding occurred, and proportion of days when downed trees were used for arboreal lichen feeding); and (3) tree characteristics between sites where feeding intensity was low and sites where it was moderate to high for all sample days combined (arboreal lichen abundance, tree diameter, tree species, and whether trees were alive or dead). Downed branches were excluded from this latter analysis as they would have had far less lichen than entire trees. Sites at which a combination of feeding types occurred ( $7 \%$ of sites) were excluded from comparisons of feeding intensity. For statistical analyses, we used t-tests for continuous variables, Mann-Whitney U tests for discrete variables on ordinal scales, and chi-square tests for discrete variables on nominal scales.

\section{Results}

We completed $20891 \mathrm{~m}$ of trailing on 12 days (153 - $3653 \mathrm{~m} /$ day), at elevations of 1560 to $2326 \mathrm{~m}$ (mean $=1971 \mathrm{~m}, \mathrm{SE}=57)$. Within this, we recorded 816 feeding sites for an average of $25.6 \mathrm{~m}$ of travel per feeding site. Cladonia was the dominant terrestrial lichen found at feeding sites, and examinations of bite marks suggested feeding was focused on it (i.e., it was not present simply because it had not been eaten). Caribou ate Grouseberry (Vaccinium scoparium), which maintains its green foliage in winter, at all but one shrub or shrub-combination site. Heather (Cassiope mertensiana, Phyllodoce empetriformis, or $P$. glanduliflora) was eaten in combination with Cladonia at one site and in combination with Grouseberry at four sites. The species of arboreal lichen on standing or downed trees and downed branches was not recorded in data forms, but field notes indicated that it was almost always Bryoria spp., with Alectoria sarmentosa constituting $<1 \%$ or occasionally $<5 \%$ of the lichen per transect. Feeding occurred at 55 of the 56 downed trees and all 11 downed branches. No additional unused downed trees or branches were observed off transects within sight of observers. Moderate- to high-intensity feeding was recorded more often at downed trees than standing trees $(67 \%$ versus $25 \%$, $\left.\chi^{2}=617, P<0.001\right)$

We observed the use of arboreal lichen on standing trees, downed trees and downed branches throughout the sample period (11 November - 06 January), but shrubs and terrestrial lichen were used only between 11 November and 19 November (Table 1). During the earlier period when Caribou fed on both groundbased foods and arboreal lichen, snow depths were shallower (daily averages of $9-51 \mathrm{~cm}$ ) than the later period when they fed exclusively on arboreal lichen $(62-198 \mathrm{~cm})$, and lift paralleled this difference (Table 2 ). Mean elevations were higher during the shallowsnow period than during the deep-snow period (Table 2). During the shallow-snow period, Caribou feeding sites had a greater proportion of trees with high lichen abundance and high-intensity feeding, and trees on which foraging occurred were farther apart, in comparison to the exclusively arboreal lichen-foraging period (Table 2). There was no difference between the two periods in the proportion of days on which Caribou fed on downed trees or branches (Table 2). The mean number of Caribou per group trailed was similar between the two periods ( 2.4 for the groundforaging period, 2.1 for the exclusively arboreal lichen-foraging period; $\mathrm{t}=0.49, P=0.635$ ).

In comparison to unused standing trees, trees with moderate to high feeding intensity had greater lichen loads, larger diameter, and were more often Subalpine Fir or Engelmann Spruce and less often Alpine Larch, Whitebark Pine or Lodgepole Pine (Table 3). There was no difference in whether trees were alive or dead (Table 3). 
TABLE 1. Occurrences of each feeding type at Mountain Caribou forage sites during early winter, southern Purcell Mountains, British Columbia, 1998-1999.

\begin{tabular}{lccc}
\hline \hline & \multicolumn{3}{c}{ Percentage of Feeding Sites } \\
\cline { 2 - 3 } & $\begin{array}{c}\text { 11 November }- \\
\text { 19 November } \\
\text { Feeding Type }\end{array}$ & $\begin{array}{c}\text { 20 November } \\
\text { - 06 January } \\
(\mathrm{n}=426)\end{array}$ & $\begin{array}{c}\text { Total } \\
(\mathrm{n}=816)\end{array}$ \\
\hline Shrub & 29.5 & 0.0 & 14.1 \\
Terrestrial lichen & 0.3 & 0.0 & 0.1 \\
Shrub + terrestrial lichen & 10.8 & 0.0 & 5.1 \\
Arboreal lichen on standing tree & 50.8 & 89.0 & 70.7 \\
Arboreal lichen on standing tree + shrub & 3.6 & 0.0 & 1.7 \\
Arboreal lichen on standing tree + terrestrial lichen & 0.3 & 0.0 & 0.1 \\
Arboreal lichen on downed tree & 4.4 & 8.9 & 6.7 \\
Arboreal lichen on downed branch & 0.5 & 2.1 & 1.3 \\
\hline \hline
\end{tabular}

The data are undoubtedly autocorrelated to some degree due to many feeding sites per day being the result of a single animal or group of animals, and being close to each other. However, four to seven feeding types were observed per day on all but one day, so animals did appear to make feeding-type choices on a continual basis.

\section{Discussion}

Two modes of foraging were apparent. When snow was shallow, Caribou used Grouseberry and Cladonia located under the snow and also fed intensively on arboreal lichen at a few trees having high lichen loads. When snow was deeper and provided greater lift, Caribou fed exclusively on arboreal lichen, typically with low-intensity feeding sessions at more trees having lower lichen abundance than those used earlier.
When the green and presumably higher-protein Grouseberry was more available due to shallow snow, lichen from standing trees would have been less available due to the lack of lift. At that time, Caribou may have employed a strategy of searching for Grouseberry and restricting their use of arboreal lichen to when they happened upon either downed trees or standing trees with unusually high lichen loads. This approach would be consistent with the greater distance between feeding sites recorded here and noted by Simpson et al. (1987) prior to the onset of an exclusively arboreal lichen diet. In contrast, when snow was deep, arboreal lichen was the only available food and occurred in varying amounts on virtually every tree, so Caribou may have shifted strategies to inspect more trees in an effort to locate better lichen patches. In both cases, Caribou fed at essentially all windthrown trees and

TABLE 2. Snow and foraging characteristics on early-winter days when Mountain Caribou fed exclusively on arboreal lichen versus days when they fed on both arboreal lichen and ground-based foods (shrubs or terrestrial lichen), southern Purcell Mountains, British Columbia, 11 November 1998 - 6 January 1999.

\begin{tabular}{|c|c|c|c|c|c|c|}
\hline \multirow[b]{3}{*}{ Measure } & \multicolumn{4}{|c|}{ Foraging Mode } & \multirow[b]{3}{*}{ Test } & \multirow[b]{3}{*}{$P$} \\
\hline & \multicolumn{2}{|c|}{$\begin{array}{l}\text { Arboreal Lichen \& Ground } \\
\text { Forage ( } \leq 19 \text { November) }\end{array}$} & \multicolumn{2}{|c|}{$\begin{array}{l}\text { Arboreal Lichen Only } \\
\quad(\geq 20 \text { November })\end{array}$} & & \\
\hline & $\mathrm{n}$ & value & $\mathrm{n}$ & value & & \\
\hline Mean snow depth $(\mathrm{cm})+/-\mathrm{SE}$ & 27 & $32(3)$ & 34 & $143(6)$ & $t$ & $<0.001$ \\
\hline $\begin{array}{l}\text { Mean lift (snow depth - } \\
\text { sinking depth }[\mathrm{cm}])+/- \text { SE }\end{array}$ & 27 & $9(2)$ & 34 & $109(7)$ & $t$ & $<0.001$ \\
\hline $\begin{array}{l}\text { Elevation }(\mathrm{m}) \text { at midpoint of } \\
\text { daily trailing segment }+/ \text { - SE }\end{array}$ & 5 & $2100(84)$ & 7 & $1878(59)$ & $t$ & 0.049 \\
\hline $\begin{array}{l}\text { Arboreal lichen abundance }\left(5: 4: 3: 2: 1: 0^{1}\right) \\
\text { at standing-tree sites }(\%)\end{array}$ & 198 & $0: 35: 43: 20: 1: 0$ & 379 & $0: 7: 48: 41: 4: 0$ & $U$ & $<0.001$ \\
\hline $\begin{array}{l}\text { Feeding intensity }\left(4: 3: 2^{2}\right) \\
\text { at standing tree sites }(\%)\end{array}$ & 211 & $7: 40: 53$ & 376 & $2: 15: 83$ & $U$ & $<0.001$ \\
\hline $\begin{array}{l}\text { Mean distance between arboreal } \\
\text { lichen } \operatorname{sites}^{3}(\mathrm{~m})+/-\mathrm{SE}\end{array}$ & 225 & $52(7)$ & 440 & $21(3)$ & $U$ & $<0.001$ \\
\hline $\begin{array}{l}\text { Days downed trees used: } \\
\text { days not observed to be used }\end{array}$ & 5 & $4: 1$ & 7 & $5: 2$ & $\chi^{2}$ & 0.735 \\
\hline
\end{tabular}

${ }^{1}$ based on Armleder et al. (1992)

24 = high, 3 = moderate, 2 = low

${ }^{3}$ standing tree, downed tree or downed branch sites 
TABLE 3. Characteristics of standing trees where Caribou feeding did not occur versus standing trees where feeding intensity was moderate to high, southern Purcell Mountains, British Columbia, 11 November 1998 - 6 January 1999.

\begin{tabular}{|c|c|c|c|c|}
\hline \multirow[b]{2}{*}{ Measure } & \multicolumn{2}{|c|}{ Feeding Intensity } & \multirow[b]{2}{*}{ Test } & \multirow[b]{2}{*}{$P$} \\
\hline & None $(\mathrm{n}=94)$ & Moderate-High $(\mathrm{n}=136)$ & & \\
\hline Arboreal lichen abundance $5: 4: 3: 2: 1: 0^{1}(\%)$ & $0: 6: 28: 35: 28: 3$ & 0:29:51:21:0:0 & $U$ & $<0.001$ \\
\hline Mean tree diameter $(\mathrm{cm})+/-\mathrm{SE}$ & $25.2(1.3)$ & $29.5(1.3)$ & $U$ & 0.045 \\
\hline Tree species Bl:Se:Pl:Pa:La² $(\%)$ & $46: 15: 20: 10: 10$ & $74: 23: 2: 2: 0$ & $\chi^{2}$ & $<0.001$ \\
\hline Live trees: dead trees $(\%)$ & $88: 12$ & $85: 15$ & $\chi^{2}$ & 0.420 \\
\hline
\end{tabular}

${ }^{1}$ based on Armleder et al. (1992)

${ }^{2} \mathrm{Bl}=$ Subalpine Fir, $\mathrm{Se}=$ Engelmann Spruce, $\mathrm{Pl}=$ Lodgepole Pine, $\mathrm{Pa}=$ Whitebark Pine, La = Alpine Larch

branches encountered, used downed trees more intensively than they did standing trees, and used them to the same degree in the low-snow and deep-snow periods. Consistent with our results, Rominger and Oldemeyer (1990) found the diet to shift away from ground-based food sources when snow depth exceeded $50 \mathrm{~cm}$.

The simplest explanation for the patterns we observed is that it reflected the typical annual shift from a mixed early-winter diet to an arboreal lichen-only late-winter diet, with the early date of the shift resulting from the $50-\mathrm{cm}$ snowpack we observed in midNovember being four weeks ahead of normal at $1930 \mathrm{~m}$ elevation in our study area (British Columbia Ministry of Environment, Lands and Parks Snow Survey Bulletin, 01 February 2000, unpublished data). However, the same snow data suggest that even the normal date for that snowpack (the threshold preventing ground-feeding) in the southern Purcell Mountains would be roughly a month earlier than the typical late-winter start date of mid-January. The same is true for the Revelstoke population of Mountain Caribou, in which the $50-\mathrm{cm}$ mark is surpassed on early-winter ranges in early December (Stevenson et al. 2001), a month before the ascent to late-winter ranges (Apps et al. 2001). Furthermore, animals we trailed moved downslope to an elevation of $<1900 \mathrm{~m}$ when they began using only arboreal lichen. This is considerably below either the early-winter or late-winter averages reported for this study area (about 1950 to $2150 \mathrm{~m}$; Apps and Kinley $2000^{*}$ ), and is counter to the normal pattern of ascending from early-winter to late-winter habitats reported both for Mountain Caribou generally (Apps et al. 2001; Stevenson et al. 2001) and in the southern Purcell Mountains specifically (Apps and Kinley $\left.2000^{*}\right)$. Finally, arboreal lichen from windthrown trees and branches continued to be well-used throughout our study period. Thus, the data suggest that both the mixed-foraging strategy and that of eating only arboreal lichen (with considerable emphasis on downed trees and branches) are part of the early-winter foraging pattern for Caribou in the southern Purcell Mountains. This implies that early winter is characterized by considerable intra-season variability in foraging modes. Early winter foraging is presumably distinct from the late-winter foraging pattern that focuses almost entirely on arboreal lichen from standing trees, described above.

Foraging patterns, particularly feeding intensity and distance between feeding sites, might be influenced by group size, so absolute values reported here may have been related to the small groups we trailed. In addition, differences in sampling methods make detailed comparisons among studies difficult. In spite of those issues, some comparisons can be made to early-winter patterns recorded at similar scales elsewhere in Mountain Caribou range. The larger diameter of trees on sites or transects where Caribou fed relative to where they did not feed was also reported by McLellan and Flaa (1993*) but not by Mowat et al. (1998*), and below but not within subalpine forest by Ashcroft (1997*). The greater arboreal lichen abundance on used trees was also found elsewhere (Mowat et al. 1998*; Terry et al. 2000). Differences in tree species composition between used sites and unused or random sites have not been reported outside of the Purcell Mountains (McLellan and Flaa 1993*; Mowat et al. 1998*; Terry et al. 2000). Similar to our results, Terry et al. (2000) did not find live:dead tree ratios to differ relative to Caribou use, but Ashcroft (1997*) noted greater Caribou use with increasing proportions of live trees in some habitat types. Although we have made incidental observations of Caribou using Falsebox and forbs in early winter within this study area in other years, they were not recorded during this study. Falsebox use has been reported within some populations (McLellan and Flaa 1993*; Mowat et al. 1998*), but not others (Ashcroft 1997*). We are not aware of any other records of Grouseberry use within the range of this ecotype. Another major contrast between our results and those reported elsewhere was that we observed no use of habitats below the subalpine forest (although that is not always true for this study area; T. Kinley, unpublished data). The contrasts with other populations probably relate both to permanent environmental factors related to our study area's location on the somewhat drier southeastern edge of Mountain Caribou range and to conditions in the year of the study, in which snow accumulated rapidly. However, the emphasis on downed trees and branches or litterfall 
during early winter is consistent with the findings of Simpson et al. (1987), Rominger and Oldemeyer (1989), McLellan and Flaa (1993*), Ashcroft (1997*), Mowat et al. (1998*), and Terry et al. (2000), and is predictable given the greater lichen availability when trees are horizontal than when they are vertical. Rominger et al. (2000) found that Caribou could not maintain adequate forage intake in early winter without the presence of windthrown trees. During early winter, it becomes increasingly difficult to obtain groundbased foods as snowpacks deepen, yet lift is not yet adequate to reach the zone of abundant arboreal lichen high in trees, so arboreal lichen from sources other than standing trees may be essential. The apparent decline in the use of arboreal lichen fragments on the snow or on downed trees and branches during late winter likely relates not only to the increasing availability of lichen on standing trees, but also to a decreasing availability of downed arboreal lichen in late winter. A decrease in downed sources of arboreal lichen would be expected during late winter due to more stable weather (fewer storms with accompanying winds), frozen ground (less chance of roots breaking free of the soil), and attrition of the weaker trees, branches or lichen fragments by that point.

Patterns of tree selection at the foraging-path scale differed slightly from those noted for coarser spatial scales in the same study area. Apps and Kinley (2000*) found that, at a range of "landscape-level" scales, Caribou selected forests that contained Subalpine Fir, Whitebark Pine and Alpine Larch, showed nil to slightly positive selection for Engelmann Spruce, and nil to negative selection for Lodgepole Pine in early winter. At a scale that compared used to random sites 300 to 900 m apart, Kinley and Apps (2000*) similarly found a preference for Alpine Larch and Whitebark Pine, but no selection relative to Engelmann Spruce, Subalpine Fir or Lodgepole Pine. In contrast, results presented here indicate a preference for Engelmann Spruce and Subalpine Fir relative to Alpine Larch, Whitebark Pine and Lodgepole Pine (Table 3). Differences among spatial scales in habitat selection by Woodland Caribou have been reported elsewhere (Rettie and Messier 2000; Apps et al. 2001). In addition to potentially being artifacts of among-scale differences in the definitions or physical configuration of "available" habitat, these differences may reflect hierarchical reactions by Caribou to limiting factors. Coarser-scale selection may relate to avoiding factors that are most limiting, such as predation, with finerscale choices being related to factors that have a less catastrophic impact, such as food availability (Rettie and Messier 2000). In our study area, arboreal hair lichen, Grouseberry and terrestrial lichen are available to varying degrees across a broad range of elevations. However, lower elevations are used in winter by Moose (Alces alces), Elk (Cervus elaphus), Mule Deer (Odocoileus hemionus), and White-tailed Deer (Odocoileus virginianus) (Edwards 1956; Hudson et al. 1976) and therefore the Cougars (Felis concolor) and Gray Wolves (Canis lupus) that feed upon them. Predation has been a major limiting factor in several Mountain Caribou populations (Seip 1992; Kinley and Apps 2001). Caribou in the southern Purcell Mountains are likely influenced by a higher-level need to minimize predation risk by remaining at upper elevations; i.e., forests with a high Alpine Larch and Whitebark Pine component at the subalpine forest - subalpine parkland ecotone. In such locations, Gray Wolves and Cougars are nearly absent in winter, and lines of sight are aided by the open forest and little understory extending above the snowpack, improving the ability to avoid Wolverines (Gulo gulo), the only predator remaining at high elevations during winter. At the opposite end of the habitat-selection spectrum, Caribou make finerscale decisions along foraging paths that relate to maximizing feeding opportunities, such as selecting tree species that provide a better substrate for lichen growth. Subalpine Fir and Engelmann Spruce have many low branches and evergreen needles to support lichen within reach of Caribou, whereas older trees of both pine species and Alpine Larch are typically devoid of live lower branches and Alpine Larch sheds its needles prior to winter. Thus, our results should be considered within a hierarchical framework of habitat selection.

\section{Management Implications}

Maintaining early-winter forage for Mountain Caribou in the southern Purcell Mountains will involve retaining the old forest stands that have abundant Grouseberry and arboreal lichen and significant rates of windthrow among lichen-bearing trees. Despite early-winter habitat typically being in the upper subalpine forest or the subalpine parkland, where overall timber values are presumably lower, Caribou select large individual Subalpine Fir and Engelmann Spruce trees, which can be economically valuable, and were recorded at the lower limit of the subalpine forest. Thus, when applying broader-scale models to determine areas where timber harvesting is to be excluded or modified for the benefit of Mountain Caribou (Stevenson et al. 2001), field-based inspections will also be essential to ensure that the reserves or management areas selected include characteristics suitable for early-winter foraging. They must also span a broad range of elevations. Given the greater movement between feeding sites observed during the groundforaging period, relatively large areas of subalpine forests and parkland should be designated for management as early-winter habitat. Determining the temporal extent of ground-based foraging and the elevational range of both early-winter foraging modes in years of more typical snow accumulation, and determining the energetic costs associated with early winter, would clarify the relative importance of this period. This would aid future habitat management and protection decisions. 


\section{Acknowledgments}

Funding for this research was provided by Resources Inventory Program grants from Forest Renewal British Columbia to the East Kootenay Environmental Society and Tembec Industries Inc., as part of the Purcell Caribou Project. We thank A. Levesque, M. Belcher, M. Panian, P. Cowtan and K. Eichenberger for arranging funding and administering the project; B. McLellan and J. Flaa for advice on sampling procedures; K. Hebert and L. Earl for aerial telemetry; and D. Heard and an anonymous reviewer for thorough and helpful reviews of an earlier draft.

\section{Documents Cited [marked $*$ in text]}

Apps, C. D., and T. A. Kinley. 2000. Multi-scale habitat associations of mountain caribou in the southern Purcell Mountains, British Columbia. Prepared for East Kootenay Environmental Society, Kimberley, British Columbia, and Tembec Industries Inc., Cranbrook, British Columbia. 34 pages.

Ashcroft, G. 1997. Mountain caribou behaviour and microhabitat characteristics in the Quesnel Highland. Prepared for Ministry of Environment, Lands and Parks, Williams Lake, British Columbia. 30 pages.

Committee on the Status of Endangered Wildlife in Canada. 2002. Canadian species at risk, May 2002. Canadian Wildlife Service, Environment Canada, Ottawa, Ontario. 39 pages.

Conservation Data Centre. 2003. Rangifer tarandus pop. 1. http://srmwww.gov.bc.ca/cdc/tracking.htm. Viewed November 2003.

Hatter, I., D. Butler, A. Fontana, D. Hebert, T. Kinley, S. McNay, B. Nyberg, D. Seip, J. Surgenor, M. Tanner, L. Williams, G. Woods, J. Woods, and J. Young. 2002. A strategy for the recovery of mountain caribou in British Columbia. Version 1.0. Ministry of Water, Land and Air Protection, Victoria, British Columbia. 73 pages.

Kinley, T. A., and C. D. Apps. 2000. Selection for stand-level forest attributes by mountain caribou in the southern Purcell Mountains, British Columbia. Prepared for East Kootenay Environmental Society, Kimberley, British Columbia, and Tembec Industries Inc., Cranbrook, British Columbia. 19 pages.

McLellan, B. N., and J. Flaa. 1993. Integrating mountain caribou and forestry - the Revelstoke caribou project. E.P. 1161. Annual report year one. Ministry of Forests, Revelstoke, British Columbia. 34 pages.

Mowat, G., T. Kinley, and S. Pendray. 1998. Caribou site level habitat selection and home range patterns in the North Thompson watershed of British Columbia. Prepared for Ministry of Environment, Lands and Parks, Kamloops, British Columbia. 46 pages.

United States Fish and Wildlife Service. 1994. Recovery plan for woodland caribou in the Selkirk Mountains. United States Department of the Interior, Portland, Oregon. 71 pages.

\section{Literature Cited}

Antifeau, T. D. 1987. The significance of snow and arboreal lichen in the winter ecology of mountain caribou (Rangifer tarandus caribou) in the North Thompson watershed of British Columbia. MSc thesis, University of British Columbia, Vancouver, British Columbia. 142 pages.
Apps, C. D., B. N. McLellan, T. A. Kinley, and J. P. Flaa. 2001. Scale-dependent habitat selection by mountain caribou, Columbia Mountains, British Columbia. Journal of Wildlife Management 65: 65-77.

Armleder, H. M., S. K. Stevenson, and S. D. Walker. 1992. Estimating the abundance of arboreal forage lichens. Land Management Handbook Field Guide Insert 7, Ministry of Forests, Victoria, British Columbia. 22 pages.

Bloomfield, M. I. 1979. The ecology and status of mountain caribou and caribou range in central British Columbia. MSc thesis, University of Alberta, Edmonton, Alberta. 318 pages.

Curran, M. P., T. F. Braumandl, and D. L. DeLong. 1992. Climatic regions and biogeoclimatic zones of the Nelson Forest Region. Pages 29-43 in A field guide for site identification for the Nelson Forest Region. Compiled and edited by T. F. Braumandl and M. P. Curran. Land Management Handbook 20, Ministry of Forests, Victoria, British Columbia. 311 pages.

Edmonds, E. J. 1991. Status of woodland caribou in western North America. Rangifer Special Issue 7: 91-107.

Edwards, R. Y. 1956. Snow depths and ungulate abundance in the mountains of western Canada. Journal of Wildlife Management 20: 150-168.

Edwards, R. Y., and R. W. Ritcey. 1960. Foods of caribou in Wells Gray Park, British Columbia. Canadian FieldNaturalist 74: 3-7.

Edwards, R. Y., J. Soos, and R. W. Ritcey. 1960. Quantitative observations on epidendric lichens used as food by caribou. Ecology 41: 425:431.

Freddy, D. J. 1974. Status and management of the Selkirk caribou herd, 1973. MSc thesis, University of Idaho, Moscow, Idaho. 132 pages.

Goward, T. 1998. Observations on the ecology of the lichen genus Bryoria in high elevation conifer forests. Canadian Field-Naturalist 112: 496-501.

Heard, D. C., and K. L. Vagt. 1998. Caribou in British Columbia: a 1996 status report. Rangifer Special Issue 10: 117-123.

Hudson, R. J., D. M. Hebert, and V. C. Brink. 1976. Occupational patterns of wildlife on a major East Kootenay winter-spring range. Journal of Range Management 29: 38-43.

Kinley, T. A., and C. D. Apps. 2001. Mortality patterns in a subpopulation of endangered mountain caribou. Wildlife Society Bulletin 29: 158-164.

Rettie, W. J., and F. Messier. 2000. Hierarchical habitat selection by woodland caribou: its relationship to limiting factors. Ecography 23: 466-478.

Rominger, E. M., and J. L. Oldemeyer. 1989. Early-winter habitat of woodland caribou, Selkirk Mountains, British Columbia. Journal of Wildlife Management 53: 238-243.

Rominger, E. M., and J. L. Oldemeyer. 1990. Early-winter diet of woodland caribou in relation to snow accumulation, Selkirk Mountains, British Columbia, Canada. Canadian Journal of Zoology 68: 2691-2694.

Rominger, E. M., C. T. Robbins, M. A. Evans, and D. J. Pierce. 2000. Autumn foraging dynamics of woodland caribou in experimentally manipulated habitats, northeastern Washington, USA. Journal of Wildlife Management 64: 160-167.

Seip, D. R. 1992. Factors limiting woodland caribou populations and their interrelationships with wolves and moose in southeastern British Columbia. Canadian Journal of Zoology 70: 1494-1503. 
Simpson, K., K. Hebert, and G. P. Woods. 1987. Critical habitats of caribou (Rangifer tarandus caribou) in the mountains of southern British Columbia. Wildlife Working Report WR-23, Ministry of Environment and Parks, Victoria, British Columbia. 12 pages.

Stevenson, S. K., H. M. Armleder, M. J. Jull, D. G. King, B. N. McLellan, and D. S. Coxson. 2001. Mountain caribou in managed forests: recommendations for managers. Second edition. Wildlife Report R-26, Ministry of Environment, Lands and Parks, Victoria, British Columbia. 76 pages.
Stevenson, S. K., and D. F. Hatler. 1985. Woodland caribou and their habitat in southern and central British Columbia. Volume 1. Land Management Report 23, Ministry of Forests, Victoria, British Columbia. 355 pages.

Terry, E. L., B. N. McLellan, and G. S. Watts. 2000. Winter habitat ecology of mountain caribou in relation to forest management. Journal of Applied Ecology 37: 589-602.

Received 26 February 2001

Accepted 15 December 2003 